\title{
Early Childhood Teachers' Pedagogical Content Knowledge in Mathematics: A Research Report from China
}

\author{
Fang Tian ${ }^{1,2}$, Jin Huang, ${ }^{1, *}$ \\ ${ }^{1}$ Department of Early Childhood Education, East China Normal University, China \\ ${ }^{2}$ Department of Early Childhood Education, Shaanxi Xueqian Normal University, China
}

Received October 7, 2019; Revised October 24, 2019; Accepted October 27, 2019

Copyright $@ 2019$ by authors, all rights reserved. Authors agree that this article remains permanently open access under the terms of the Creative Commons Attribution License 4.0 International License

\begin{abstract}
The focus on Pedagogical Content Knowledge (PCK) of pre-school teachers is a breakthrough point to promote teacher's professional development and quality of early childhood education. Based on an investigation of PCK of 161 pre-school teachers from Shanghai, this study described the level of PCK for early mathematics (PCK-EM) of pre-school teachers and examined the influence of their background on the level of PCK-EM. Further, the study put forward implications and suggestions on improving and promoting early mathematics education.
\end{abstract}

Keywords Pre-school Teachers, Mathematics, Pedagogical Content Knowledge (PCK)

\section{Introduction}

Many studies [1] on teacher development research have indicated that teachers, children, environment and teaching materials are the four elements that affect educational activities. Among the four, teachers' professional knowledge is the most significant element that affects young children's learning and an important indicator of teaching quality. Shulman [2] proposed that there is a type of knowledge specific to teaching. He pointed out that pedagogical content knowledge (PCK) is teachers' integration of subject knowledge and teaching knowledge in the process of teaching. Since then, some studies [3] confirmed the importance of evaluating teachers' PCK for mathematics, and found that teachers who have a good command of PCK for mathematics are capable of using professional mathematical language to clarify concepts and inspire students to think. Some studies $[4,5]$ confirmed teachers' PCK level was positively correlated with students' mathematics achievement and played a strong predictive role. McCray [6] found PCK-EM evaluation was also proved to reflect knowledge required for effective teaching in early mathematics.

In the context of new curriculum revolution, Theme- or Project-Based Approaches and Integration Curriculum based on children's life experience, require teachers to integrate the five domains ${ }^{1}$ in early child education and embed them into the curriculum. To achieve that, teachers should have a good understanding and command of key concepts in each domain, especially in mathematics1. Huang [7] found there are some challenges in early mathematics education, such as "a lack of mathematics" and "developmental delay of mathematical cognition in young children". To address these issues, this study applied PCK-EM survey to examine pre-school teachers' PCK-EM in terms of three domains, knowledge of content (what), knowledge of children (who), and knowledge of pedagogy (how) and offered implications and suggestions for improving and optimizing early mathematics education in China.

\section{Methods}

\subsection{Participants}

Random sampling was conducted to select 14 model kindergartens ${ }^{2}, 15$ level one kindergartens and 12 level two kindergartens in Shanghai. A total of 161 teachers from K2

\footnotetext{
${ }^{1}$ Note: Five domains: health; literacy; social; science; art.

2 Note: Model kindergartens: the highest rank of kindergartens.
} 
classes with 4 from each kindergarten participated in the study. All teachers are female with the average age of 35 years and years of teaching of 13. Teachers' years of teaching, educational background, title, and kindergartens' rank are displayed in Table 1:

Table 1. Background Information of Teachers

\begin{tabular}{|c|c|c|c|}
\hline & Category & Frequency & Percentage (\%) \\
\hline \multirow{3}{*}{$\begin{array}{l}\text { Years of } \\
\text { Teaching }\end{array}$} & $1-5$ & 53 & 32.9 \\
\hline & $5-15$ & 39 & 24.2 \\
\hline & $>15$ & 69 & 42.9 \\
\hline \multirow{4}{*}{ Education } & Associate & 62 & 38.5 \\
\hline & Bachelor1 & 9 & 5.6 \\
\hline & Bachelor2 & 88 & 54.7 \\
\hline & Graduate & 2 & 1.2 \\
\hline \multirow{5}{*}{$\begin{array}{l}\text { Professional } \\
\text { Ranking }\end{array}$} & NA & 29 & 18.0 \\
\hline & Low & 4 & 2.5 \\
\hline & Medium & 54 & 33.5 \\
\hline & $\begin{array}{c}\text { Medium } \\
\text { high }\end{array}$ & 72 & 44.7 \\
\hline & High & 2 & 1.2 \\
\hline \multirow{3}{*}{$\begin{array}{c}\text { Rank of } \\
\text { Kindergarten }\end{array}$} & High & 56 & 34.8 \\
\hline & Medium & 60 & 37.2 \\
\hline & Low & 45 & 28 \\
\hline
\end{tabular}

Note: Bachelor1: in the process of pursuing the degree; Bachelor2: already obtained the degree.

\subsection{Measure}

The PCK-EM survey includes an early mathematics teaching video clip, a PCK-EM questionnaire related to the video clip and a coding manual. The teaching video clip was provided by the Chinese researchers and was discussed and confirmed by the Chinese and the U.S. experts in early mathematics education. The questionnaire and coding manual was provided by Erikson Institute and translated and proofread by several Chinese doctoral students.

Teachers were invited to watch an authentic mathematics teaching video clip, and then respond to nine questions related to the video. Questions 1-3 are about content knowledge (what); questions 4-6 are about knowledge of students (who); questions 7-9 are about knowledge of pedagogy (how). Reliability analysis showed that Cronbach's Alpha for the questionnaire was 0.722. All the questions were open-ended and teachers were encouraged to express their ideas or opinions based on their understanding of the videos. Each teacher watched the video and completed the questionnaire independently. There was no limitation on either the number of times teachers could review the videos, or the amount of time taken to complete the questionnaire. After the valid questionnaire was collected, the researchers scored the narrative response of each question on a 1-7 scale. A score of 1-2, 3-5 and 6-7 indicates low, medium and high level, respectively. Coding manual provided specific definition on grade 1, 3, 5, 7 to ensure the objectivity of scoring, according to whether teachers were able to answer the question (s), the details of teachers' answers and their associations with early mathematical concepts and teachers' explanations. All questionnaires were scored and discussed by two raters with the ICC value of 0.727 .

Table 2. Means and Standard Deviations of Teacher's PCK in Mathematics

\begin{tabular}{cccccc}
\hline PCK Components & N & Mean & SD & Min & Max \\
\hline What & 161 & 9.1140 & .89364 & 6.33 & 11.67 \\
Who & 161 & 10.1758 & 1.88896 & 5.00 & 16.00 \\
How & 161 & 10.5301 & 1.89781 & 3.67 & 17.50 \\
\hline
\end{tabular}

\section{Results}

The total score of each of the three components (what, who, how) was 21 respectively, but the majority of teachers were scored between 8 and 10 and did not achieve a high level. These results showed that in general, teachers had a general and limited understanding of pedagogical content knowledge. As shown in Table 2, in terms of the three aspects, teachers' had the highest scores in knowledge of pedagogy but with a medium level and the lowest in content knowledge.

The GLM-General Factorial ANOVA analysis showed that the difference among teachers' achievement in the three domains was significant $[F(2,159)=35.317$, $\mathrm{p}<0.001]$. The further Pos hoc analysis indicated that the difference between each of the two domains (what vs. who, who vs. how and what vs. how) was significant $(p<0.0001)$. The highest was how, followed by who, and the lowest was what, as shown in Table 3.

Table 3. Mean Comparison among What, Who, and How

\begin{tabular}{llccc}
\hline & & Mean Difference & Standard Error & Sig- \\
\hline \multirow{2}{*}{ What } & Who & $-6.317^{*}$ & .724 & $.000^{* * *}$ \\
& How & $-8.497^{*}$ & .770 & $.000^{* * *}$ \\
\multirow{2}{*}{ Who } & How & $-2.126^{*}$ & .604 & $.000^{* * *}$ \\
\hline
\end{tabular}

Table 4 showed that the only factor that significantly contributed to teachers' early mathematics PCK was the rank of the kindergarten in which teachers worked [F (2) 7.24, $\mathrm{p}<.001]$. Specifically, teachers' PCK-EM scores positively correlated with their kindergartens' rank. Teachers from kindergartens with a higher rank achieved higher PCK scores. None of the other factors, including teachers' educational level, years of teaching or title, made a significant difference. 
Table 4. Main Effect of Teacher’s Background on PCK

\begin{tabular}{lcccc}
\hline & df & Chi Square & F & Sig- \\
\hline Years of Teaching & 2 & 699.033 & 1.323 & .269 \\
Education Level & 3 & 1831.334 & 3.466 & .065 \\
Professional Ranking & 4 & 501.252 & .949 & .390 \\
Rank of K indergarten & 2 & 3822.822 & 7.235 & $.001^{* * *}$ \\
\hline
\end{tabular}

\section{Discussion}

\subsection{Pre-school Teachers Generally had a lack of a Deep Understanding of PCK-EM \\ "WHAT"}

Based on the analysis of teachers' narrative responses in the PCK questionnaires, we found that teachers' understanding of mathematical concepts was not systematic, but scattered and isolated. Teachers' answers had a lack of critical analysis or extended explanation. Most of their understanding of early mathematical concepts was at the level of general and limited understandings of content knowledge, which is consistent with previous findings [8] that pre-school teachers are not proficient in content knowledge. Previous study also suggested that the profound understanding of fundamental mathematics is the most important requirement for pre-school teachers.

\section{"WHO”}

Teachers could not adequately explain children's learning. Most of teachers' answers focused on general teaching methods, but not mathematical concepts. For example, several teachers responded "the teacher in the video clip provided children with the opportunity to explore and select familiar materials based on their interests and learning characteristics". Even though the answer focused on children's learning that was related to mathematical concepts, teachers tended to describe children's behavior and performance and explained their understanding of PCK-EM at a shallow and general level.

\section{"HOW"}

Most teachers could observe the teaching behaviors in the video clip based on their command of mathematics concepts and expressed their views, however, they just described or repeated the teaching behaviors or language in the clip and provided a shallow explanation and general comment. They hardly explained how the teaching strategies or methods could promote children's command of mathematical concepts. Findings showed that teachers had a lack of provision of appropriate supportive strategies, which is consistent with another study [9] on the quality of teacher-child interaction using CLASS for this sample. The study found that teachers achieved a medium level in terms of their emotional support, classroom management and educational support. Among the three domains, teachers had the lowest score in educational support. Findings indicate that good teacher-child interaction depends on teachers' ability to observe and understand children's behavior as well as provide different support to individual children. The high level of the ability develops from teachers' PCK.

\subsection{The Promotion of PCK-EM for Pre-school Teachers Depends on the Quality of Kindergartens}

As shown in our study, the only factor that significantly contributed to the teachers' early math PCK was the rank of the kindergarten in which teachers worked $[\mathrm{F}(2,159)=$ $7.24, \mathrm{p}<.001$ ] but none of the other factors, such as education level, years of teaching or title. Teachers from model kindergartens achieved remarkably better PCK-EM scores that those from level one and level two kindergartens. The causes are multifaceted. Firstly, teachers' PCK-EM is a comprehensive ability, which is based on the interplay of the three components (What, Who, How). It is consistent that there are significant correlations among the three components. Therefore, the acquisition of the comprehensive ability does not merely rely on obtaining the professional knowledge, but on teaching practice and teachers' reflections on their teaching. Consequently, teachers need more support and training from the kindergartens where they worked. Secondly, since the implementation of new curriculum revolution, kindergarten-based teaching research has been a major method for promoting teacher professional development. The effect of kindergarten-based teaching research depends on the kindergarten's professional foundation, research team and resources. Tang [10] found although many kindergartens try to implement kindergarten-based teaching research, only model kindergartens have adequate funding and opportunities to cooperate with universities or research institutions, participate in special projects, and gain access to new theory and the latest research achievement. All of these factors have a good effect on kindergarten-based teaching research in model kindergartens. Thirdly, the majority of the teachers who worked in model kindergartens has a higher level of educational background and may facilitate their level of content knowledge. In conclusion, the support from the resource and environment of the kindergarten is crucial for fostering teachers' PCK-EM.

\section{Implications}

In the current implementation of the new curriculum, teacher's PCK-EM faces greater challenges because of the integration of education content, the specificity of 
individual students and the flexibility of education forms. If teachers have a clearer understanding of the key mathematics concepts, the relations among each concept, children's development trajectories of the concepts, the characteristics of children's mathematics learning in each age group, the individual differences and learning difficulties, they will have a better choice and integration of curriculum resources in order to promote children's effective learning. Thus, we put forward the following implications to help establish an effective mechanism of pre-school teachers' PCK-EM development.

First, efforts should be made to pre-service training. To strengthen and improve pre-school teachers' PCK-EM training, prospective teachers should obtain more sophisticated professional training. At the same time, universities should improve the quality of training courses and educational practice for prospective teachers in order to help them effectively integrate PCK-EM into teaching practice. We suggest that the observation+ reflection + research + practice model should be conducted to strengthen the prospective teachers' integration of PCK-EM and develop their professional knowledge and abilities.

Second, during in-service education, training and kindergarten-based teaching research should primarily focus on improving teachers' PCK-EM. The interactions within the learning community should be advocated to enhance teachers' self-reflection and encourage them to change the research focus from teaching materials, lesson preparation and lesson plans to students, learning environment and teaching strategies. During such transition, we should help teachers obtain knowledge and abilities to understand children's behaviors, analyze children's development and recognize differences among children. As a result, teachers will develop individual, practical and constructive pedagogical knowledge while studying children and reflecting on others' and their own teaching.

Finally, government should further improve and perfect the access standard for pre-school teachers in order to promote their professional knowledge and quality. At present, qualification standard for pre-school teachers is still imperfect in China. The professional requirements for pre-school teachers are at a low level, and teachers' professional development potential is limited. At the same time, there is no requirement for renewing the teaching qualification, which further restricts teachers' motivation to continue learning and their awareness of lifelong education. Therefore, in the context of developing early child education, government should realize that improving the quality of early educators is an essential prerequisite to ensure the quality of early child education. In addition, government should focus on the construction of standards for teachers' professional development and raise the access standard for pre-school teachers in order to effectively promote the quality of teachers.

\section{REFERENCES}

[1] Darlinghammond, L., \& Bransford, J. (2007). Preparing teachers for a changing world: what teachers should learn and be able to do. Jossey-Bass, An Imprint of Wiley, 106(3), 296-9.

[2] Shulman, L. S., \& Grosman, P.L. (1988). Knowledge growth in teaching: A final report to the Spencer Foundation. Stanford, CA: Stanford University.

[3] Ball, D. L. (1988). Knowledge and reasoning in mathematical pedagogy: Examining what prospective teachers bring to teacher education. Unpublished doctoral dissertation, Michigan State University, East Lansing.

[4] Hill, H. C., Rowan, B., \& Ball, D. L. (2005). Effects of teachers' mathematical knowledge for teaching on student achievement. American Educational Research Journal, 42(2).

[5] Li, P., \& Ni, Y. (2006). HLM analysis on Teacher level indicators for elementary students' mathematics performance. Teacher Education Research, 5.

[6] Author. (2011). Pedagogical content knowledge and the professional development of early child teachers. Early Child Education (educational science), 12.

[7] McCray, J. \& Chen, J. (2012). Pedagogical content knowledge for pre-school mathematics: construct validity of a new teacher interview. Journal of Research in Childhood Education, 26(3), 291-307.

[8] Ma, L. (1999). Knowing and teaching elementary mathematics: Teachers' understanding of fundamental mathematics in China and the United States. Taylor \& Francis.

[9] Huang, J. \&Tian, F. (2012). A study of Teacher-Child Interaction based on the situational half day activity in kindergarten. Shanghai Education Scientific Research, (10).

[10] Tang, J. (2013). A study of pedagogical content knowledge for pre-school teachers. Unpublished doctoral dissertation, East China Normal University, Shanghai. 